\title{
Does early improvement in depressive symptoms predict subsequent remission in patients with depression who are treated with duloxetine?
}

This article was published in the following Dove Press journal:

Neuropsychiatric Disease and Treatment

23 May 2016

Number of times this article has been viewed

\section{Akitsugu Sueki \\ Eriko Suzuki \\ Hitoshi Takahashi \\ Jun Ishigooka}

Department of Neuropsychiatry, Tokyo Women's Medical University, Tokyo, Japan
Correspondence: Hitoshi Takahashi Department of Neuropsychiatry, Tokyo Women's Medical University, 8-I Kawada-cho, Shinjuku-ku, 162-8666 Tokyo, Japan

Tel +8I 33353 8I II

Fax +81333518979

Email takahashi.hitoshi@twmu.ac.jp
Purpose: In this prospective study, we examined whether early reduction in depressive symptoms predicts later remission to duloxetine in the treatment of depression, as monitored using the Montgomery-Asberg Depression Rating Scale (MADRS).

Patients and methods: Among the 106 patients who were enrolled in this study, 67 were included in the statistical analysis. A clinical evaluation using the MADRS was performed at weeks $0,4,8,12$, and 16 after commencing treatment. For each time point, the MADRS total score was separated into three components: dysphoria, retardation, and vegetative scores.

Results: Remission was defined as an MADRS total score of $\leq 10$ at end point. From our univariate logistic regression analysis, we found that improvements in both the MADRS total score and the dysphoria score at week 4 had a significant interaction with subsequent remission. Furthermore, age and sex were significant predictors of remission. There was an increase of approximately $4 \%$ in the odds of remission for each unit increase in age, and female sex had an odds of remission of 0.318 times that of male sex (remission rate for men was $73.1 \%$ [19/26] and for women $46.3 \%$ [19/41]). However, in the multivariate model using the change from baseline in the total MADRS, dysphoria, retardation, and vegetative scores at week 4, in which age and sex were included as covariates, only sex retained significance, except for an improvement in the dysphoria score.

Conclusion: No significant interaction was found between early response to duloxetine and eventual remission in this study. Sex difference was found to be a predictor of subsequent remission in patients with depression who were treated with duloxetine, with the male sex having greater odds of remission.

Keywords: antidepressant, early response, sex difference, serotonin-noradrenalin reuptake inhibitor

\section{Introduction}

Predicting an antidepressant's outcome early is important in the treatment of depression, as it helps clinicians decide on the next-best option for pharmacotherapy as soon as possible, shortening therapeutic time, and decreasing morbidity. There is a growing body of literature suggesting that an early reduction in depressive symptoms by 2-4 weeks of treatment predicts the later response to the antidepressants. ${ }^{1-5}$

Duloxetine, a serotonin-noradrenalin reuptake inhibitor, has been widely used and is the first choice among the options available for the treatment of depression, as with selective serotonin reuptake inhibitors. ${ }^{6}$ To date, there has been only one report investigating the relationship between early improvement in depressive symptoms and eventual outcomes in the treatment with duloxetine; the study adopted a post hoc 
analysis and used the Hamilton Rating Scale for Depression (HAM-D) for assessing the clinical status of the patients. ${ }^{7}$

We here examined whether early reduction in depressive symptoms could predict later remission to duloxetine during treatment of depression in a prospective manner, using the Montgomery-Asberg Depression Rating Scale (MADRS), which is designed to be more sensitive to treatment changes in the symptomatology of depression than the HAM-D, as the primary outcome measure. ${ }^{8,9}$ Based on our previous studies, ${ }^{10,11}$ the ten items of the MADRS were classified into three factors: 1) dysphoria factor (pessimistic thoughts, suicidal thoughts, reported sadness), 2) retardation factor (lassitude, inability to feel, apparent sadness, concentration difficulties), and 3 ) vegetative factor (reduced sleep, reduced appetite, inner tension). We assessed whether early improvement in any of these factors is associated with eventual remission during the treatment of depression with duloxetine.

\section{Patients and methods Subjects}

This study was approved by Ethical Review Board in Tokyo Women's Medical University. The inclusion criteria were as follows: 1) major depressive disorder according to the Diagnostic and Statistical Manual of Mental Disorders, Fourth Edition, with a total score of $\geq 20$ on the MADRS; 2) no other Axis I or II disorder; 3 ) no treatment for the present episode; 4) $\geq 18$ years of age; 5) absence of psychotic, catatonic, or atypical features; 6) absence of postpartum onset or seasonal pattern; and 7) absence of clinically meaningful physical disease or abnormal findings on physical examination or laboratory testing. All patients who met the inclusion criteria and gave written informed consent were enrolled in this study.

\section{Treatment and assessment}

Patients were treated with duloxetine for 16 weeks. Duloxetine was administered at a dose of $20 \mathrm{mg} / \mathrm{day}$, and then the dose was adjusted in the range of $20-60 \mathrm{mg} /$ day, based on the clinical status of the patients. The starting dose of $20 \mathrm{mg} /$ day was the recommended one for the treatment of duloxetine in Japan. Other psychotropic medications were not permitted, except anxiolytics and hypnotics. Clinical status was assessed using the MADRS at weeks $0,4,8,12$, and 16. Blood samples were obtained at least 2 weeks after the final dose adjustment of duloxetine had been made. Duloxetine plasma concentrations were detected by high-performance liquid chromatography.

\section{Statistical analysis}

To analyze the data, the intent-to-treat last-observationcarried-forward method was used. Remission was defined as an MADRS total score of $\leq 10$ at the end point. To identify predictors of remission, binary logistic models of remission classification were generated, using the change in the MADRS score from baseline to that at 4 weeks as the main predictor of interest, and age, sex, body mass index, MADRS score at baseline, blood concentration of duloxetine, and duloxetine dose as secondary predictors. As the MADRS score consists of three components that are added for the total score, the dysphoria, retardation, and vegetative scores were analyzed as well.

\section{Results}

Among the total of 106 patients enrolled, 67 were included in the statistical analysis, and the other 39 patients were excluded from it for the following reasons: "no visit to our hospital after enrollment in the study" (20 patients), "stopped taking duloxetine due to side effects a few days after commencement of the study" (12 patients), "refusing to continue the study before first assessment" (three patients), and "assumption of poor adherence to the treatment because blood concentration of duloxetine was $\sim 0 \mathrm{ng} / \mathrm{mL}$ " (four patients).

Table 1 shows the patients' characteristics, and the odds ratio estimated from our univariate logistic regression analysis of remission, with each factor cited in the table as a predictor. Age and sex were found to be significantly associated with subsequent remission. Table 2 shows the association between improvement at week 4 for each of the MADRS scores and subsequent remission. From the univariate logistic regression analysis of remission, with each MADRS score as a predictor, we found that improvements in both the MADRS total score and the dysphoria score at week 4 had a significant interaction with subsequent remission. However, in the multivariate model using change in the MADRS total, dysphoria, retardation, and vegetative scores from baseline to week 4 , in which age and sex were included as covariates, only sex retained significance except for improvement in dysphoria score (Table 3). Figures 1 and 2 show the mean MADRS total and subscale scores by visit, respectively.

\section{Discussion}

From our univariate logistic regression analysis of remission based on the change in the MADRS score from baseline to week 4 as predictor, we found that improvements in both the MADRS total score and the dysphoria score at week 4 had a significant 
Table I Demographic, clinical, and treatment characteristics of patients

\begin{tabular}{|c|c|c|c|c|c|}
\hline Clinical indices & $\begin{array}{l}\text { Remitters } \\
(\mathrm{n}=\mathbf{3 8})\end{array}$ & $\begin{array}{l}\text { Non-remitters } \\
(n=29)\end{array}$ & Odds ratio & $95 \% \mathrm{Cl}$ & $P$-value \\
\hline Age, mean \pm SD (years) & $46.0 \pm 15.4$ & $37.8 \pm 15.4$ & 1.037 & $0.878-0.996$ & $0.039 *$ \\
\hline $\operatorname{Sex}(N)$ & M 19, F 19 & M 7, F 22 & 0.318 & $0.11-0.92$ & $0.035^{*}$ \\
\hline $\mathrm{BMI}$, mean $\pm \mathrm{SD}$ & $23.8 \pm 5.0$ & $22.1 \pm 4.9$ & 1.078 & $0.969-1.199$ & 0.166 \\
\hline Recurrent MDD (\%) & 40.5 & 31 & 0.66 & $0.231-1.82$ & 0.424 \\
\hline $\begin{array}{l}\text { Duloxetine dose at end point, } \\
\text { mean } \pm S D(\mathrm{mg})\end{array}$ & $45.5 \pm 18.1$ & $50.3 \pm 15.7$ & 0.983 & $0.955-1.012$ & 0.254 \\
\hline $\begin{array}{l}\text { Duloxetine plasma concentration, } \\
\text { mean } \pm S D(\mathrm{ng} / \mathrm{mL})\end{array}$ & $29.5 \pm 25.9$ & $22.8 \pm 20.8$ & 1.013 & $0.99-1.036$ & 0.2634 \\
\hline $\begin{array}{l}\text { MADRS baseline score (total), } \\
\text { mean } \pm \text { SD }\end{array}$ & $29.4 \pm 6.2$ & $32.0 \pm 6.6$ & 0.937 & $0.866-1.014$ & 0.1071 \\
\hline $\begin{array}{l}\text { MADRS baseline score } \\
\text { (dysphoria), mean } \pm S D\end{array}$ & $7.7 \pm 2.1$ & $8.0 \pm 2.6$ & 0.948 & $0.77-1.167$ & 0.6147 \\
\hline $\begin{array}{l}\text { MADRS baseline score } \\
\text { (retardation), mean } \pm \text { SD }\end{array}$ & $13.0 \pm 3.2$ & $14.4 \pm 2.6$ & 0.854 & $0.719-1.015$ & 0.0727 \\
\hline $\begin{array}{l}\text { MADRS baseline score } \\
\text { (vegetative), mean } \pm S D\end{array}$ & $8.7 \pm 2.7$ & $9.6 \pm 2.5$ & 0.865 & $0.714-1.049$ & 0.1418 \\
\hline
\end{tabular}

Notes: Odds ratios estimated from univariate logistic regression models of remission classification. *Statistically significant value $(P<0.05)$.

Abbreviations: $\mathrm{Cl}$, confidence interval; SD, standard deviation; BMI, body mass index; MDD, major depressive disorder; MADRS, Montgomery-Asberg Depression Rating Scale; $M$, male; $F$, female.

interaction with subsequent remission. Furthermore, age and sex were significant predictors of remission, with an increase of nearly $4 \%$ in the odds of remission for each unit increase in age, and with females having 0.318 times that of the males' odds of remission (remission rate for men was 73.1\% [19/26] and for women 46.3\% [19/41]; Table 1). However, in the multivariate model, using the change in the MADRS score from baseline to week 4, with age and sex included as covariates, only sex retained a significant effect, except for an improvement in the dysphoria score. The mean MADRS baseline score for males and females was $30.6 \pm 7.7$ and $30.5 \pm 5.7$, respectively, with no significant difference between them $(t=0.063, P=0.95)$.

In seven clinical trials of duloxetine $(40-120 \mathrm{mg} /$ day $)$ up to 9-week duration, Kornstein et al suggested that the magnitude of improvement in depressive symptoms did not differ significantly between male and female patients. ${ }^{12}$

Table 2 Association between improvements at week 4 in each MADRS scores and subsequent remission

\begin{tabular}{llll}
\hline Clinical indices & Odds ratio & $95 \% \mathrm{Cl}$ & P-value \\
\hline $\begin{array}{l}\text { Change in MADRS total score } \\
\text { from baseline to week 4 }\end{array}$ & 0.935 & $0.878-0.996$ & $0.038^{*}$ \\
$\begin{array}{l}\text { Change in MADRS dysphoria } \\
\text { score from baseline to week 4 }\end{array}$ & 0.787 & $0.640-0.968$ & $0.023^{*}$ \\
$\begin{array}{l}\text { Change in MADRS retardation } \\
\text { score from baseline to week 4 }\end{array}$ & 0.898 & $0.802-1.005$ & 0.06 \\
$\begin{array}{l}\text { Change in MADRS vegetative } \\
\text { score from baseline to week 4 }\end{array}$ & 0.909 & $0.779-1.060$ & 0.222 \\
\hline
\end{tabular}

Notes: Odds ratios estimated from univariate logistic regression models of remission classification. *Statistically significant value $(P<0.05)$.

Abbreviations: $\mathrm{Cl}$, confidence interval; MADRS, Montgomery-Asberg Depression Rating Scale.
Although this finding is inconsistent to ours, some previous reports assist our results in terms of sex difference. Tricyclic antidepressants, which affect both noradrenaline and serotonin reuptake inhibition, had a preferential effect in males, ${ }^{13,14}$ whereas females responded more poorly to tricyclic antidepressants than males ${ }^{13-15}$ and appeared to respond better to selective serotonin reuptake inhibitors. ${ }^{14}$ Morishita and Arita have also reported that there was a tendency for a higher rate of improvement among males than among females in the treatment of depression with

Table 3 Odds ratios estimated from multivariate logistic regression models of remission classification

\begin{tabular}{llll}
\hline Clinical indices & Odds ratio & $95 \% \mathbf{C l}$ & $P$-value \\
\hline $\begin{array}{l}\text { Change in MADRS total score } \\
\text { from baseline to week } 4\end{array}$ & 0.945 & $0.885-1.009$ & 0.0925 \\
Age & 1.032 & $0.997-1.070$ & 0.0758 \\
Sex (reference: male) & 0.314 & $0.103-0.961$ & $0.0424^{*}$ \\
$\begin{array}{l}\text { Change in MADRS dysphoria } \\
\text { score from baseline to week 4 }\end{array}$ & 0.82 & $0.663-1.014$ & 0.0672 \\
Age & 1.035 & $0.999-1.072$ & 0.0597 \\
Sex (reference: male) & 0.347 & $0.113-1.066$ & 0.0646 \\
Change in MADRS retardation & 0.914 & $0.813-1.027$ & 0.1316 \\
score from baseline to week 4 & & & \\
Age & 1.035 & $0.999-1.07 \mid$ & 0.0546 \\
Sex (reference: male) & 0.322 & $0.106-0.979$ & $0.0458^{*}$ \\
Change in MADRS vegetative & 0.918 & $0.775-1.086$ & 0.3171 \\
score from baseline to week 4 & & & \\
Age & 1.034 & $0.999-1.070$ & 0.0591 \\
Sex (reference: male) & 0.288 & $0.095-0.876$ & $0.0282^{*}$ \\
\hline Note & & &
\end{tabular}

Note: *Statistically significant value $(P<0.05)$.

Abbreviations: $\mathrm{Cl}$, confidence interval; MADRS, Montgomery-Asberg Depression Rating Scale. 


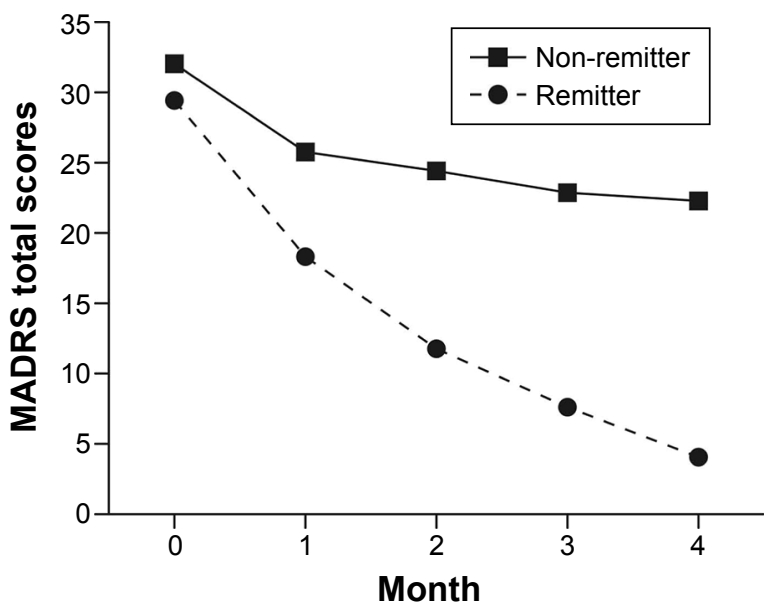

Figure I The mean MADRS total scores by visit. Abbreviation: MADRS, Montgomery-Asberg Depression Rating Scale.

milnacipran, a serotonin-noradrenalin reuptake inhibitor, when improvement was defined by a $50 \%$ reduction from the baseline total HAM-D score. ${ }^{16}$ The findings of these studies, as well as our own, may indicate that stimulating noradrenergic function is important for the treatment of depression in males.

Katz et al investigated the association between early symptom reductions of $\geq 20 \%$ in the 17 -item HAM-D score during the first 2 weeks and the subsequent remission of depression over 8 months, which was defined by a HAM-D score of $\leq 7$, in the treatment of depression with duloxetine. They suggested that a $20 \%$ improvement in the HAM-D total scores after 2 weeks of treatment with duloxetine, as well as

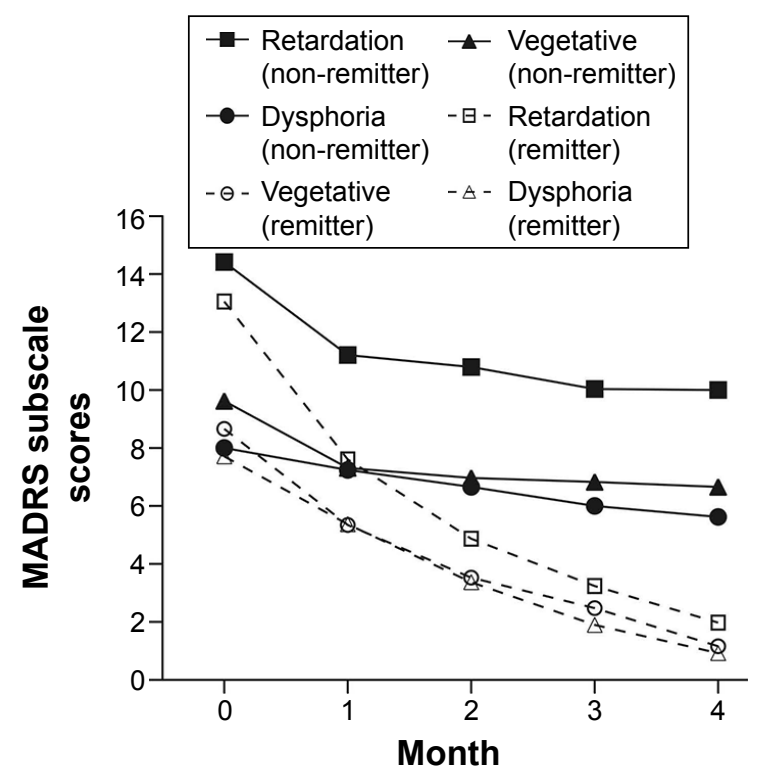

Figure 2 The mean MADRS subscale scores by visit. Abbreviation: MADRS, Montgomery-Asberg Depression Rating Scale. some factor subscales, such as the "core depression factor", including depressed mood, the "anxiety factor", and the "retardation factor", but not the "sleep factor", was predictive of sustained remission. ${ }^{7}$ Although there are numerous differences in study design between our study and that of Katz et al, including the definition of early response and the duration of the study period, our study also showed a change in the dysphoria factor score, including the subscale of depressed mood, after 4 weeks of treatment. This was highly significant as a predictor of remission in the univariate model $(P=0.023)$, but only borderline significant $(P=0.067)$ in the multivariate model. In the univariate models, a change from baseline to week 4 was borderline significant for the retardation factor $(P=0.06)$, but was quite nonsignificant for the vegetative factor $(P=0.222)$, including the sleep disturbance subscale, of the MADRS. This may suggest that early improvements in specific factors of depressive symptoms associated with depressed mood and retardation, as well as overall symptom reduction, tend to be useful values for predicting the later remission upon treatment with duloxetine.

MADRS-6 is widely recognized as one that focuses on the core symptoms of depression (as assessed by the MADRS items: apparent sadness, reported sadness, inner tension, lassitude, inability to feel, and pessimistic thoughts). An additional analysis in the univariate model showed that the change in MADRS-6 score from baseline to week 4 was a significant predictor of remission $(P=0.043)$. However, in the multivariate model with age and sex included as covariates, early reduction in MADRS-6 score had a no significant effect $(P=0.079)$.

\section{Limitations}

There are some limitations in the present study. First, the uncontrolled nature of the study design is a major limitation, which substantially limits the conclusion that can be drawn. Inclusion of a placebo control arm would have helped significantly with the interpretation of the data. Second, we did not use the \% improvement, which has often been used in similar types of reports, ${ }^{5,7}$ but adopted the change in score of the MADRS from baseline to week 4 as the definition of early response, which makes it difficult to compare our results with those of others. Similarly, rather than using the \% improvement, Sakurai et al also adopted the score change in the Quick Inventory of Depressive Symptomatology from baseline to week 2 as a predictor of early response, and investigated its association with later remission during citalopram treatment in the STAR*D trial. ${ }^{3}$ Third, the present study allowed clinicians to use some adjunctive anxiolytics and hypnotics, 
which could have contributed to a change in the clinical status of our patients. Fourth, the sample size was small, and the dropout rate was large, which may have affected the validity of our results. There are some previous reports focusing on the same field as ours, in which the number of patients included is $\sim 100 .{ }^{17,18}$ Although we decided sample size of this study according to those reports described, more appropriate approach for sample size determination should have been adopted.

\section{Conclusion}

To date, this is the first study investigating whether early symptom changes could predict later remission among patients with depression receiving duloxetine treatment, adopting the MADRS for clinical assessment. No significant interaction was found between early MADRS score reduction during the first 4 weeks and eventual remission at 16 weeks with the treatment with duloxetine. When separating the MADRS score into its three components, viz the dysphoria, retardation, and vegetative factors, we also did not find any significant association between early improvement in any of these factors and the final treatment outcomes. On the other hand, sex difference was found to be a predictor of subsequent remission in patients with depression who were treated with duloxetine, with males more likely to undergo remission than females.

\section{Acknowledgment}

The authors would like to specially thank Takayuki Abe, $\mathrm{PhD}$, Keio University Hospital and Clinical and Translational Research Center, for data analysis.

\section{Disclosure}

The authors report no conflicts of interest in this work.

\section{References}

1. Katz MM, Tekell JL, Bowden CL, et al. Onset and early behavioral effects of pharmacologically different antidepressants and placebo in depression. Neuropsychopharmacology. 2004;29:566-579.
2. Stassen HH, Angst J, Hell D, et al. Is there a common resilience mechanism underlying antidepressant drug response? Evidence from 2848 patients. J Clin Psychiatry. 2007;68:1195-1205.

3. Sakurai H, Uchida H, Abe T, et al. Trajectories of individual symptoms in remitters versus non-remitters with depression. J Affect Disord. 2013; 151:506-513.

4. Nierenberg AA, Farabaugh AH, Alpert JE, et al. Timing of onset of antidepressant response with fluoxetine treatment. Am J Psychiatry. 2000; 157:1423-1428.

5. Papakostas GI, Petersen T, Sklarsky KG, et al. Timing of clinical improvement and symptom resolution in the treatment of major depressive disorder. Psychiatry Res. 2007;149:195-200.

6. Monteleone F, Caputo M, Tecce MF, et al. Duloxetine in the treatment of depression: an overview. Cent Nerv Syst Agents Med Chem. 2011; $11: 174-183$

7. Katz MM, Meyers AL, Prakash A, et al. Early symptom change prediction of remission in depression treatment. Psychopharmacol Bull. 2009;42:94-107.

8. Senra C. Evaluation and monitoring of symptom severity and change in depressed outpatients. J Clin Psychol. 1996;52:317-324.

9. Mulder RT, Joyce PR, Frampton C. Relationships among measures of treatment outcome in depressed patients. J Affect Disord. 2003;76: $127-135$.

10. Suzuki A, Aoshima T, Fukasawa T, et al. A three-factor model of the MADRS in major depressive disorder. Depress Anxiety. 2005;21:95-97.

11. Kamata M, Suzuki A, Yoshida K, et al. Genetic polymorphisms in the serotonergic system and symptom clusters of major depressive disorder. J Affect Disord. 2011;135:374-376.

12. Kornstein SG, Wohlreich MM, Mallinckrodt CH, et al. Duloxetine efficacy for major depressive disorder in male vs. female patients: data from 7 randomized, double-blind, placebo-controlled trials. J Clin Psychiatry. 2006;67:761-770.

13. Coppen A, Whybrow PC, Noguera R, et al. The comparative antidepressant value of L-tryptophan and imipramine with and without attempted potentiation by liothyronine. Arch Gen Psychiatry. 1972;26:234-241.

14. Kornstein SG, Schatzberg AF, Thase ME, et al. Gender differences in treatment response to sertraline versus imipramine in chronic depression. Am J Psychiatry. 2000;157:1445-1452.

15. Old Age Depression Interest Group. How long should the elderly take antidepressants? A double-blind placebo-controlled study of continuation/prophylaxis therapy with dothiepin. Br J Psychiatry. 1993; 162:175-182.

16. Morishita S, Arita S. Differential effects of milnacipran, fluvoxamine and paroxetine for depression, especially in gender. Eur Psychiatry. 2003; 18:418-420.

17. Tomita T, Yasui-Furukori N, Sato Y, et al. Sex differences in the prediction of the effectiveness of paroxetine for patients with major depressive disorder identified using a receiver operating characteristic curve analysis for early response. Neuropsychiatr Dis Treat. 2014;10:599-606.

18. Vermeiden M, Kamperman AM, Vulink ME, et al. Early improvement as a predictor of eventual antidepressant treatment response in severely depressed inpatients. Psychopharmacology (Berl). 2015;232: $1347-1356$.
Neuropsychiatric Disease and Treatment

\section{Publish your work in this journal}

Neuropsychiatric Disease and Treatment is an international, peerreviewed journal of clinical therapeutics and pharmacology focusing on concise rapid reporting of clinical or pre-clinical studies on a range of neuropsychiatric and neurological disorders. This journal is indexed on PubMed Central, the 'PsycINFO' database and CAS,

\section{Dovepress}

and is the official journal of The International Neuropsychiatric Association (INA). The manuscript management system is completely online and includes a very quick and fair peer-review system, which is all easy to use. Visit http://www.dovepress.com/testimonials.php to read real quotes from published authors. 